\title{
3-(2-BENZOTHIAZOLYLAZO)THENOYLTRIFLUORO ACETONE AND ITS Cu(II), Co(II), Ni(II) AND Zn(II) COMPLEXES
}

\author{
ParakkulangaraThrithodi Malini ${ }^{1}$, Muhammed Basheer Ummathur ${ }^{2, \bigotimes}$, \\ Damodaran Kamalakshy Babu ${ }^{1}$ and Krishnannair Krishnankutty ${ }^{3}$ \\ ${ }^{1} \mathrm{PG}$ and Research Department of Chemistry, Zamorin's Guruvayurappan College, \\ Calicut-673014, (Kerala) India \\ ${ }^{2}$ PG Department of Chemistry, KAHM Unity Women's College, Manjeri-676122, (Kerala) India \\ ${ }^{3}$ Department of Chemistry, University of Calicut, Thenhippalam-673635, (Kerala) India \\ ${ }^{\square}$ Corresponding Author: mbummathur@gmail.com
}

\begin{abstract}
The coupling of diazotized 2-aminobenzothiazole with thenoyltrifluoroacetone resulted in the formation of a tridentate ligand (HL). Azo-enol tautomeric form of the compound with intramolecular hydrogen bond is confirmed by spectral and analytical data. Formation of its $\left[\mathrm{CoL}_{2}\right],\left[\mathrm{NiL}_{2}\right],[\mathrm{CuL}(\mathrm{OAc})]$ and $\left[\mathrm{ZnL}_{2}\right]$ complexes with monobasic tridentate coordination is also proposed based on analytical and spectral data. Magnetic studies revealed that $\mathrm{Cu}(\mathrm{II})$, $\mathrm{Ni}(\mathrm{II})$ and $\mathrm{Co}(\mathrm{II})$ complexes are paramagnetic while the $\mathrm{Zn}(\mathrm{II})$ chelate is diamagnetic.
\end{abstract}

Keywords: Benzothiazolylazo Derivative, Thenoyltrifluoroacetone, Azo-enol Form, Metal Complexes, Spectral Studies.

RASĀYANJ. Chem., Vol. 14, No.3, 2021

\section{INTRODUCTION}

Thenoyltrifluoroacetone is a $\beta$-diketone and an inhibitor of cellular respiration. ${ }^{1,2}$ Studies indicate that it inhibits carboxylesterase and mitochondrial complex II activities. ${ }^{2,3}$ It has been investigated as a better complexing agent than acetylacetone for the separation and purification of various metal ions ${ }^{3}$. Diazo coupling of aryldiazonium ion with 1,3-dicarbonyls is used for preparing many important fabric dyes and pigments. ${ }^{4,5}$ In heteroarylazo derivatives of $\beta$-diketones, the heteroatom can donate electron pair to metal cation due to proximity effects. ${ }^{6-8}$ Literature is extensive on the structural aspects of complexes of azo- $\beta$ diketones and allied compounds. ${ }^{6-14}$ However, reports are scanty on heteroarylazo derivatives of thenoyltrifluoroacetone. As a part of our interest in the study of heteroarylazo derivatives of 1,3dicarbonyl compounds and their metal complexes, the present report communicates the synthesis and characterization of a new type of tridentate azodye obtained by coupling diazotized 2-aminobenzothiazole with thenoyltrifluoroacetone. ${ }^{6-8,14} \mathrm{Co}(\mathrm{II}), \mathrm{Ni}(\mathrm{II}), \mathrm{Cu}(\mathrm{II})$ and $\mathrm{Zn}(\mathrm{II})$ complexes of this ligand are also synthesized and characterized.

\section{Material and Methods}

\section{EXPERIMENTAL}

The elemental analysis was done by microanalyses (Heraeus Elemental analyzer) and AAS (Perkin Elmer 2380 spectrometer $)$. The electronic spectra of the compounds in methanol $\left(10^{-4} \mathrm{~mol} / \mathrm{L}\right)$ were recorded on a 1601 Shimadzu UV-Vis. spectrophotometer, IR spectra ( $\mathrm{KBr}$ discs) on an 8101 Shimadzu FTIR spectrophotometer, ${ }^{1} \mathrm{H}$ NMR spectra $\left(\mathrm{CDCl}_{3}\right.$ or DMSO-d $\left.{ }_{6}\right)$ on a Varian $300 \mathrm{NMR}$ spectrometer and mass spectra on a Jeol/SX-102 mass spectrometer (FAB using argon and meta-nitrobenzyl alcohol as the matrix $)$. Molar conductance of the complexes was determined in $\mathrm{DMF}\left(\sim 10^{-3} \mathrm{~mol} / \mathrm{L}\right)$ at room temperature. Magnetic susceptibilities were determined at room temperature on a Guoy type magnetic balance at room temperature using $\mathrm{Hg}\left[\mathrm{Co}(\mathrm{NCS})_{4}\right]$ as the standard. 2-Aminobenzothiazole, thenoyltrifluoroacetone, methanol, urea and metal acetates used were of AR grade. 
RASĀYAN J. Chem.

Vol. 14 | No. 3 |2111-2115| July - September | 2021

\section{Preparation of 3-(2-benzothiazolylazo)thenoyltrifluoroacetone (HL)}

An aqueous solution of benzothiazole-2-diazonium ion was synthesized. ${ }^{15}$ After destroying the excess nitrous acid with urea, the diazonium salt solution $(0.01 \mathrm{~mol})$ was added slowly with stirring to an icecold solution of thenoyltrifluoroacetone $(0.01 \mathrm{~mol}$ in $25 \mathrm{~mL}$ ethanol). Cold $\mathrm{NaOH}$ solution $(1 \mathrm{M}, 20 \mathrm{~mL})$ was added dropwise to maintain the $\mathrm{pH}$ of the mixture around 5. After continuous stirring of about half an hour, the precipitated compound was filtered and washed several times with deionized water till the coprecipitated sodium sulphate was completely removed. The crude product was recrystallized twice from hot benzene to get chromatographically pure material (TLC on silica gel, the solvent was acetone). The compound was crystalline and is soluble in common organic solvents.

\section{Synthesis of $\mathrm{Ni}(\mathrm{II}), \mathrm{Co}(\mathrm{II}), \mathrm{Cu}(\mathrm{II})$ and $\mathrm{Zn}(\mathrm{II})$ Complexes}

To a solution of the ligand $(0.02 \mathrm{~mol}$ in $20 \mathrm{~mL}$ methanol) a concentrated aqueous solution of metal(II) acetate $(0.01 \mathrm{~mol})$ was added and stirred for $\sim 2 \mathrm{~h}$. The precipitated complex was filtered, washed with water, recrystallized from hot chloroform and dried in a vacuum.

\section{RESULTS AND DISCUSSION}

The elemental analytical data indicate 1:1 ratio for the diazo coupled product (HL) of diazotized 2aminobenzothiazole and thenoyltrifluoroacetone (Fig.-1). [ $\left.\mathrm{ML}_{2}\right]$ stoichiometry of the Co(II), Ni(II) and $\mathrm{Zn}$ (II) complexes (Fig.-2) is evident from the analytical data (Table-1) and their non-electrolytic nature in DMF solvent (specific conductance $<10 \Omega^{-1} \mathrm{~cm}^{-1} ; 10^{-3} \mathrm{M}$ solution). $\mathrm{Cu}(\mathrm{II})$ complex has [CuL(OAc)] stoichiometry (Fig.-3). The $\mathrm{Zn}$ (II) chelate is diamagnetic, as expected, while all other complexes showed paramagnetic moments within the range.

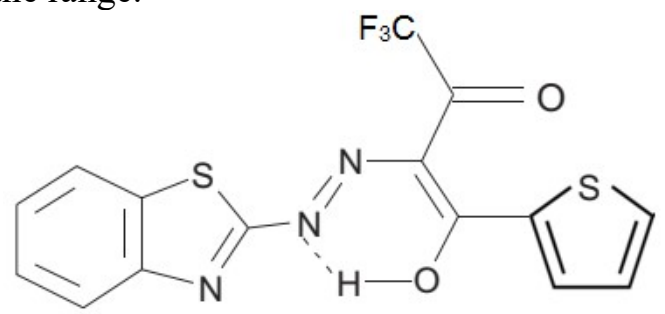

Fig.-1: The Proposed Structural Formula of HL

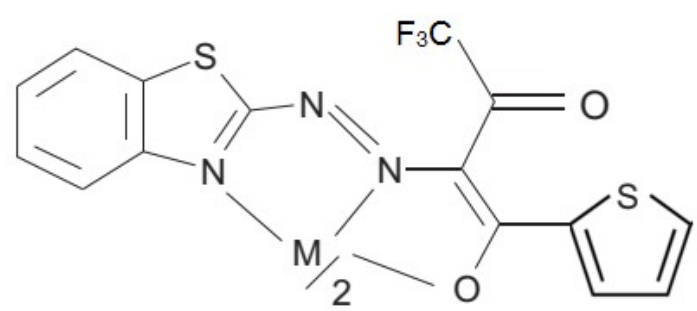

Fig.-2: The Proposed Structural Formula of the Metal Complexesof HL; M = Co(II), Ni(II) and Zn(II)

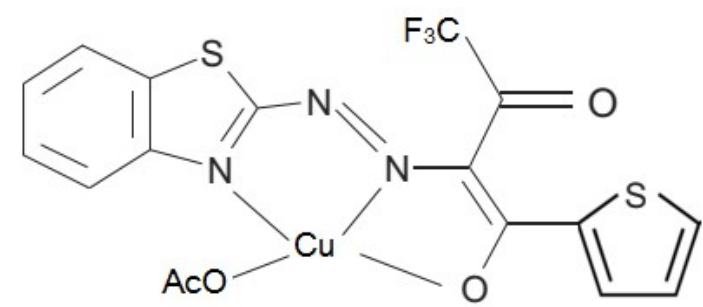

\section{IR Spectra}

Fig.-3: The Proposed Structural Formula of the Cu(II) Complex of HL

The free carbonyl band of the trifluoroacetyl group of HL appears at $1705 \mathrm{~cm}^{-1} .^{13,16,17}$ The observed free carbonyl stretching frequency strongly supports the fact that the free carbonyl group in unsymmetrical 1,3-dicarbonyls is the one in which the carbonyl oxygen is less electron-rich. The strong band observed at 
$1640 \mathrm{~cm}^{-1}$ is due to the stretching of the enolised carbonylgroup. ${ }^{14} \mathrm{C}-\mathrm{O}-\mathrm{H}$ in-plane bending and $v(\mathrm{~N}=\mathrm{N})$ are observed at 1280 and $1455 \mathrm{~cm}^{-1}$ respectively as two medium intensity bands. ${ }^{16,17}$ The $v(\mathrm{C}=\mathrm{N})$ of benzothiazole ring is observed at $1620 \mathrm{~cm}^{-1}$ and $\mathrm{v}(\mathrm{C}=\mathrm{C})$ of the aryl ring appeared at $1580 \mathrm{~cm}^{-1}$. The broad band in the range $2500-3500 \mathrm{~cm}^{-1}$ confirms strong intramolecular hydrogen bonding in the compound. Thus the IR spectrum of HL supports the intramolecular hydrogen-bonded azo-enol tautomeric form of the compound as in Fig.-1.

Table-1: Physical and Analytical data of HL and its Metal Complexes

\begin{tabular}{|c|c|c|c|c|c|c|}
\hline \multirow{2}{*}{$\begin{array}{l}\text { Compound/ Empirical } \\
\text { formula }\end{array}$} & \multirow{2}{*}{ Yield\% } & \multirow{2}{*}{ M.P. ${ }^{0} \mathrm{C}$} & \multicolumn{4}{|c|}{ Elemental Analysis:Found (Calculated)\% } \\
\hline & & & $\mathrm{C}$ & $\mathrm{H}$ & $\mathrm{N}$ & $\mathrm{M}$ \\
\hline $\mathrm{HLC}_{15} \mathrm{H}_{8} \mathrm{~F}_{3} \mathrm{~N}_{3} \mathrm{~S}_{2} \mathrm{O}_{2}$ & 55 & 135 & $\begin{array}{c}46.60 \\
(46.90) \\
\end{array}$ & $\begin{array}{l}2.15 \\
(2.00) \\
\end{array}$ & $\begin{array}{c}10.50 \\
(10.90) \\
\end{array}$ & - \\
\hline $\begin{array}{c}{[\mathrm{CuL}(\mathrm{OAc})]} \\
\mathrm{C}_{17} \mathrm{H}_{10} \mathrm{CuF}_{3} \mathrm{~N}_{3} \mathrm{~S}_{2} \mathrm{O}_{4}\end{array}$ & 65 & 225 & $\begin{array}{l}39.85 \\
(40.43) \\
\end{array}$ & $\begin{array}{c}1.82 \\
(1.98)\end{array}$ & $\begin{array}{c}8.90 \\
(8.32)\end{array}$ & $\begin{array}{c}12.01 \\
(12.59)\end{array}$ \\
\hline $\begin{array}{c}{\left[\mathrm{CoL}_{2}\right]} \\
\mathrm{C}_{30} \mathrm{H}_{14} \mathrm{CoN}_{6} \mathrm{~F}_{6} \mathrm{~S}_{4} \mathrm{O}_{4}\end{array}$ & 70 & 210 & $\begin{array}{c}42.75 \\
(43.74)\end{array}$ & $\begin{array}{c}1.65 \\
(1.70)\end{array}$ & $\begin{array}{c}11.20 \\
(10.20)\end{array}$ & $\begin{array}{c}6.90 \\
(7.16)\end{array}$ \\
\hline $\begin{array}{c}{\left[\mathrm{NiL}_{2}\right]} \\
\mathrm{C}_{30} \mathrm{H}_{14} \mathrm{~N}_{6} \mathrm{NiF}_{6} \mathrm{~S}_{4} \mathrm{O}_{4} \\
\end{array}$ & 65 & 200 & $\begin{array}{c}43.20 \\
(43.75) \\
\end{array}$ & $\begin{array}{c}1.52 \\
(1.70) \\
\end{array}$ & $\begin{array}{c}10.81 \\
(10.21) \\
\end{array}$ & $\begin{array}{c}6.52 \\
(7.14) \\
\end{array}$ \\
\hline $\begin{array}{c}{\left[\mathrm{ZnL}_{2}\right]} \\
\mathrm{C}_{30} \mathrm{H}_{14} \mathrm{~N}_{6} \mathrm{~F}_{6} \mathrm{~S}_{4} \mathrm{ZnO}_{4}\end{array}$ & 75 & 205 & $\begin{array}{c}43.10 \\
(43.40)\end{array}$ & $\begin{array}{c}1.72 \\
(1.69)\end{array}$ & $\begin{array}{c}9.70 \\
(10.13)\end{array}$ & $\begin{array}{c}7.15 \\
(7.89)\end{array}$ \\
\hline
\end{tabular}

In the IR spectra of all the metal complexes, the free carbonyl band of the ligand is only slightly shifted. This indicates that the free carbonyl group is not involved in metal coordination. The band due to the hydrogen-bonded carbonyl group of the ligand vanishes and a new band appeared at $\sim 1570 \mathrm{~cm}^{-1}$ supporting the involvement of the enolised carbonyl group in bonding with the metal ion. ${ }^{18}$ The free ligand band observed at $1280 \mathrm{~cm}^{-1}$ due to $\mathrm{C}-\mathrm{O}-\mathrm{H}$ bending and the broad free ligand band in the region $2500-3500 \mathrm{~cm}^{-1}$ disappeared in the spectra of all the metal complexes. Both these factors strongly support the replacement of enol proton of the ligand by metal ion during complex formation. ${ }^{6,7,18}$ Several medium intensity bands are observed in the $2500-3500 \mathrm{~cm}^{-1}$ region of the spectra assignable to various $v(\mathrm{C}-\mathrm{H})$ vibrations. In the spectra of the complexes, the bands due to $v(\mathrm{~N}=\mathrm{N})$ and benzothiazole $v(\mathrm{C}=\mathrm{N})$ of the ligand shifted appreciably to lower wave numbers indicating the coordination of these groups in bonding with the metal ion as in Fig.-2 and Fig.-3 (Table-2).

IR spectrum of the $\mathrm{Cu}$ (II) complex showed a comparatively strong band at $1625 \mathrm{~cm}^{-1}$ and a medium intensity band at $1310 \mathrm{~cm}^{-1}$ due to the antisymmetric and symmetric stretching of monodentate acetate group respectively as in Fig.-3. ${ }^{6,7,18}$ The appearance of new medium intensity bands in the 420-480 and $530-580 \mathrm{~cm}^{-1}$ region of the spectra due to $v(\mathrm{M}-\mathrm{O})$ and $v(\mathrm{M}-\mathrm{N})$ also support Fig.-2 and Fig.-3. ${ }^{18}$

Table-2: Characteristic IR Stretching Bands $\left(\mathrm{cm}^{-1}\right)$ of HL and its Metal Complexes

\begin{tabular}{c|c|c|c|c|c|c}
\hline Compound & Free $(\mathrm{C}=\mathrm{O})$ & Chelated $(\mathrm{C}=\mathrm{O})$ & $(\mathrm{C}=\mathrm{N})$ & $(\mathrm{N}=\mathrm{N})$ & $(\mathrm{M}-\mathrm{N})$ & $(\mathrm{M}-\mathrm{O})$ \\
\hline $\mathrm{HL}$ & 1705 & 1640 & 1620 & 1455 & - & - \\
\hline$[\mathrm{CuL}(\mathrm{OAc})]$ & 1705 & 1570 & 1598 & 1435 & 538 & 432,472 \\
\hline$\left[\mathrm{CoL}_{2}\right]$ & 1710 & 1568 & 1590 & 1433 & 547 & 412,476 \\
\hline$\left[\mathrm{NiL}_{2}\right]$ & 1710 & 1572 & 1594 & 1430 & 545 & 425,475 \\
\hline$\left[\mathrm{ZnL}_{2}\right]$ & 1708 & 1566 & 1586 & 1428 & 578 & 420,478 \\
\hline
\end{tabular}

\section{${ }^{1}$ H NMR Spectra}

The intramolecular hydrogen-bonded enol proton of HL appeared as a low field one proton signal at $\delta$ $14.10 \mathrm{ppm} .{ }^{6,7,19}$ This signal disappeared in the ${ }^{1} \mathrm{H}$ NMR spectrum of the diamagnetic Zn(II) complex, indicating the replacement of enol proton by metal ion during chelate formation. ${ }^{6,7}$ The aryl protons appeared like a complex multiplet in the range $\delta 6.8$ to $8.1 \mathrm{ppm}$.

\section{Mass Spectra}

The presence of an intense molecular ion peak at $\mathrm{m} / \mathrm{z} 383$ in the mass spectrum of HL confirms the formulation of the compound as in Fig.-1. The azo structure of the compound is evident from the presence of the peak due to the elimination of $\mathrm{ArN}_{2}$ from molecular ion. ${ }^{7,20}$ Fragments due to the elimination of 
$\mathrm{CF}_{3} \mathrm{CO}$ and $\mathrm{C}_{4} \mathrm{H}_{3} \mathrm{SCO}$ are also present in the spectrum. The observed peak at $m / z 175$ is due to the ion radical through the elimination of $\mathrm{CF}_{3} \mathrm{CO}$ and $\mathrm{C}_{4} \mathrm{H}_{3} \mathrm{SCO}$ from $\mathrm{P}^{+}$. This peak also rules out the existence of the compound in the hydrazone form because in such case the most facile reaction will be the cleavage of $\mathrm{N}-\mathrm{N}$ bond ${ }^{8,21}$. Thus the peaks observed in the spectrum strongly support the existence of the compound in the azo-enol form rather than in the keto-hydrazone form.

$[\mathrm{CuL}(\mathrm{OAc})]$ and $\left[\mathrm{NiL}_{2}\right]$ stoichiometry of the $\mathrm{Cu}(\mathrm{II})$ and $\mathrm{Ni}(\mathrm{II})$ complexes are revealed from the presence of corresponding molecular ion peaks in their $\mathrm{FAB}$ mass spectra. Peaks due to $\left[\mathrm{P}-\mathrm{CF}_{3} \mathrm{CO}\right]^{+},[\mathrm{P}-$ $\left.\mathrm{C}_{4} \mathrm{H}_{3} \mathrm{SCO}\right]^{+},\left[\mathrm{C}_{4} \mathrm{H}_{3} \mathrm{SCO}\right]^{+},\left[\mathrm{CF}_{3} \mathrm{CO}\right]^{+},[\mathrm{ML}]^{+}, \mathrm{L}^{+}$and fragments of $\mathrm{L}^{+}$are present in the spectra. The peaks due to the removal of the acetate group and several fragments containing copper in the 3:1 natural abundance of ${ }^{63} \mathrm{Cu}$ and ${ }^{65} \mathrm{Cu}$ isotopes are also present in the mass spectrum of the $\mathrm{Cu}(\mathrm{II})$ complex. The important mass spectral fragments are tabulated in Table-3.

Table-3: Mass Spectral Data of HL and its $\mathrm{Cu}(\mathrm{II})$ and Ni(II) Complexes

\begin{tabular}{c|l}
\hline Compound & \multicolumn{1}{|c}{ Mass Spectral Data $(\mathrm{m} / \mathrm{z})$} \\
\hline $\mathrm{HL}$ & $383,286,272,221,175,111,97$ \\
\hline$[\mathrm{CuL}(\mathrm{OAc})]$ & $506,504,409,407,447,445,395,393,383,336,334,298,296,286,239$, \\
\hline$\left[\mathrm{NiL}_{2}\right]$ & $837,175,111,97$ \\
\hline
\end{tabular}

\section{Electronic Spectra}

Various $n \rightarrow \pi^{*}$ and $\pi \rightarrow \pi^{*}$ transitions are confirmed by two broad bands with maxima at $380 \mathrm{~nm}$ and 270 $\mathrm{nm}$ in the UV spectrum of HL. In the spectra of metal complexes, these values shifted slightly to a longer wavelength indicating the involvement of carbonyl and azo groups in metal complexation. ${ }^{12}$

$\mathrm{Cu}$ (II) complex displayed a broad visible band at $15,000 \mathrm{~cm}^{-1}$. This, along with the measured $\mu_{\text {eff }}$ value (1.75 B.M.), supports its square-planar structure. ${ }^{22}$ The Ni(II) chelate shows three well-separated absorption bands in the spectrum at $\lambda_{\max } 8,200,13,100$ and $24,300 \mathrm{~cm}^{-1}$ corresponding to the transitions; ${ }^{3} \mathrm{~A}_{2 \mathrm{~g}} \rightarrow{ }^{3} \mathrm{~T}_{2 \mathrm{~g}} ;{ }^{3} \mathrm{~A}_{2 \mathrm{~g}} \rightarrow{ }^{3} \mathrm{~T}_{1 \mathrm{~g}}(\mathrm{~F})$ and ${ }^{3} \mathrm{~A}_{2 \mathrm{~g}} \rightarrow{ }^{3} \mathrm{~T}_{1 \mathrm{~g}}(\mathrm{P})$ respectively. ${ }^{6}$ These, together with their measured $\mu_{\text {eff }}$ value (2.80 BM), support the octahedral structure of the complex. The spectrum of the Co(II) complex showed three bands at $\lambda_{\max } 9,500,12,000$ and $20,000 \mathrm{~cm}^{-1}$ corresponding to the transitions ${ }^{4} \mathrm{~T}_{1 \mathrm{~g}}(\mathrm{~F}) \rightarrow{ }^{4} \mathrm{~T}_{2 \mathrm{~g}} ;{ }^{4} \mathrm{~T}_{1 \mathrm{~g}}(\mathrm{~F})$ $\rightarrow{ }^{4} \mathrm{~A}_{2 \mathrm{~g}} ;{ }^{4} \mathrm{~T}_{1 \mathrm{~g}}(\mathrm{~F}) \rightarrow{ }^{4} \mathrm{~T}_{1 \mathrm{~g}}(\mathrm{P})$, respectively. The transition to ${ }^{4} \mathrm{~A}_{2 \mathrm{~g}}$ is very weak and appears as a shoulder. This, together with the measured $\mu_{\text {eff }}$ value (4.82 BM.), suggest its octahedral geometry. ${ }^{23}$

\section{CONCLUSION}

A new arylazo derivative (HL) is prepared by coupling benzothiazole-2-diazonium ion with the active methylene group of thenoyltrifluoroacetone. Analytical and spectral data confirmed its existence in the azo-enol tautomeric form in which the carbonyl group bearing the benzothiazole group has enolized and hydrogen-bonded to one of the azo nitrogen, and the carbonyl group of trifluoroacetyl group remained in the keto form. Monobasic tridentate coordination of the compound involving cyclic nitrogen, one of the azo nitrogen and the enolate oxygen has been confirmed from the analytical and spectral data of the metal chelates. The $\mathrm{Cu}(\mathrm{II})$ complex conforms to [CuL(OAc)] stoichiometry while $\mathrm{Co}(\mathrm{II}), \mathrm{Ni}(\mathrm{II})$ and $\mathrm{Zn}(\mathrm{II})$ complexes are in agreement with $\left[\mathrm{ML}_{2}\right]$ stoichiometry.

\section{ACKNOWLEDGEMENT}

The authors are thankful to University Grants Commission, New Delhi, India for providing financial assistance. Thanks are due to RSIC, CDRI, Lucknow; IIT, Mumbai; and RSIC, IIT, Chennai for providing analytical and spectral facilities.

\section{REFERENCES}

1. J.G. Wu, R.W. Deng and Z.N. Chen, Transition Metal Chemistry, 18, 23(1993), http://doi.org/10.1007/BF00136042

2. H.O. Byun, H.Y. Kim, J.J. Lim, Y.H. Seo and G. Yoon, Journal of Cellular Biochemistry, 104(5), 1747(2008), http://doi.org/10.1002/jcb.21741

3. J. G. Zhang and N.W. Fariss, Biochemical Pharmacolology, 63(4), 751(2002), http://doi.org/10.1016/s0006-2952(01)00871-1 
RASĀYAN J. Chem.

Vol. 14 | No. 3 |2111-2115| July - September | 2021

4. N. Oger, E.L. Grognec and F.X. Felpin, Organic Chemistry Frontiers, 2, 590(2015), https://doi.org/10.1039/C5QO00037H

5. K.H. Saunders and R.L.M. Allen, Aromatic Diazo compounds, $3^{\text {rd }}$ Edn., Edward Arnold, London, (1985).

6. M.B. Ummathur, D.K. Babu and K. Krishnankutty, Journal of Serbian Chemical Society, 79(3), 303(2014), https://doi.org/10.2298/JSC121227042U

7. K. Krishnankutty, M.B. Ummathur and D.K. Babu, Journal of Serbian Chemical Society, 75(5), 639(2010), https://doi.org/10.2298/JSC090816040K

8. M.B. Ummathur, Polish Journal of Chemistry, 83, 1717(2009).

9. J. Legendziewicz, G. Oczko, R. Wiglusz and V. Amirkhanov, Journal of Alloys and Compounds, 323-324, 792(2001), https://doi.org/10.1016/S0925-8388(01)01147-1

10. K. Krishnankutty and D.K. Babu, Journal of Indian Chemical Society, 73, 379(1996).

11. M. Cheriyan and K. Mohanan, Asian Journal of Chemistry, 19(4), 2831(2007).

12. R. Pallikkavil, M.B. Ummathur and K. Krishnankutty, Turkish Journal of Chemistry, 37(6), 889(2013), https://doi.org/10.3906/kim-1301-19

13. K. Krishnankutty, M. B. Ummathur, D. K. Babu and P.M. Philip, Journal of Iranian Chemical Research, 2, 111(2009).

14. K. Krishnankutty and D.K. Babu, Journal of Indian Chemical Society, 73, 379(1996).

15. R.C. Elderfield, Heterocyclic Compounds, John Wiley, New York, p.555 (1950).

16. L.J. Bellamy, The Infrared Spectra of Complex Molecules, Chapman and Hall, London, (1980).

17. C.N.R. Rao, Chemical Applications of Infrared Spectroscopy, Academic Press, London, (1963).

18. N. Nakamoto, Infrared Spectra and Raman Spectra of Inorganic and Coordination Compounds, John Wiley \& Sons, New York, (1997).

19. K. Mohanan, N. Subhadrambika, R.S. Joseyphus, S.S. Swathy and V.P. Nisha, Journal of Saudi Chemical Society, 20(4), 379(2016), https://doi.org/10.1016/j.jscs.2012.07.007

20. M. Zayed, G.G. Mohamed and M.A. Fahmey, Journal of Thermal Analysis and Calorimetry, 107(2), 763(2012), https://doi.org/10.1007/s10973-011-1515-8

21. H.T. Tang, Y.B. Zhou, Y. Zhu, H.C. Sun, M. Lin and Z.P. Zhan, Chemistry- An Asian Journal, 9(5), 1278(2014), https://doi.org/10.1002/asia.201400037

22. J. Manonmani, R. Thirumuruhan, K. Muthusamy, N. Vengidusamy, R. Siva, P. Mondikalipudur, G. Shanmugam and H.K. Fun, Polyhedron, 20, 3039(2001), https://doi.org/10.1016/S02775387(01)00901-9

23. K.S. Abou-Melha, Journal of Coordination Chemistry, 61, 2053(2010), https://doi.org/10.1080/00958970701862167

[RJC-6292/2020] 